\title{
Multiple Sets of Pulse Adjustment Control Technique Based on Input Voltage Feed-forward Compensation for DC-DC Converters
}

\author{
Ming Qin ${ }^{\mathrm{a}}$, Jingchao $\mathrm{Li}^{\mathrm{b}}$
}

School of Electrical Engineering, Zhengzhou University, Zhengzhou 450001, China;

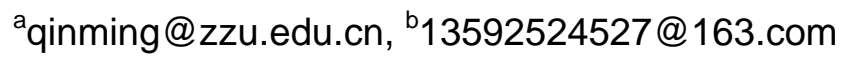

Keywords: input voltage feed-forward, pulse adjustment, DC-DC converters.

\begin{abstract}
In order to increase the applicable input voltage scope of Pulse Adjustment (PA) controlled converter, a new control technique for DC-DC converters, Multiple Sets of Pulse Adjustment Based on Input Voltage Feed-forward Compensation (IVF-MSPA), is proposed in this paper. By introducing input voltage feed-forward compensation, at the beginning of each switching period IVF-MSPA controller senses the input voltage of the DC-DC converter and selects one among multiple sets of control pulses. Each set of control pulses is composed of high-power pulse and low-power pulse. The high-power pulse or low-power pulse is selected to drive the power switch by sensing the output voltage of the DC-DC converter at the beginning of each switching period. The principle and operational process of IVF-MSPA control technique are introduced in the paper. The control regulation and steady-state performance of IVF-MSPA controlled Boost converter operating in discontinuous conduction mode ( DCM ) are studied. The proportions of IVF-MSPA and PA control pulses as the function of input voltage within one repetition cycle are analyzed. Simulation and experimental results are presented to verify the feasibility and advantages of IVF-MSPA control technique as well as the correctness of the theoretical analysis. Research results show that the IVF-MSPA controlled converter enjoys excellent steady and transient state performance as well as the wider input voltage scope.
\end{abstract}

\section{Introduction}

In recent years, the countries around the world are facing such outstanding problems as the energy crisis and environmental degradation. It is crucial to use all kinds of energy comprehensively and efficiently for future sustainable energy supply. Our country per-capital share of oil resources is far lower than the world average, there is an obvious oil energy gap. At the same time, such as fog and water pollution environment problems also affect the national economy and people's livelihood which need to be solved in urgent. Therefore, further studying a series of technology problems of new energy is the key to sustainable development and solving energy shortage. Clean fuels such as solar and wind energy is concerned, clean energy power generation technology is developing rapidly and has a clear future. Compared with the traditional thermal power, clean energy power generation system has the advantages of renewable, no pollution, high degree of automation, but due to the influence of natural environment, its output characteristic is more complex, the power quality is difficult to guarantee, not directly provide electricity equipment. So specific power transformation technology is usually used, DC-DC switching technology (that is DC-DC switching converter) is one important part of it. Due to the nonlinear characteristics of photovoltaic array, the output voltage of photovoltaic array is affected by light intensity, environmental temperature and load conditions ${ }^{[1-7]}$. Therefore, it is necessary to study a DC switching converter technique which can adapts to changes in wide range input source voltage.

In recent decades, Pulse Width Modulation (PWM) technique based on the classical linear control theory is widely used in the field of switch converter technology, but its performance in transient characteristics and stability is poor, thus some scholars put forward a kind of new control technique which is based on nonlinear control regulation called Pulse Adjustment (PA). Compared with the conventional PWM, PA control technique has more excellent transient performance and stability, but the PA controlled converter by a combination of two different control pulses has the 
drawback of relatively narrow range of input voltage which limits its application in photovoltaic field ${ }^{[8-12]}$. Then some modified pulse adjusting control technique mainly focus on the features of optimizing the output characteristic of the controlled converter which also does not apply to the occasions required wide range input voltage ${ }^{[13-15]}$. In order to solve this problem, the paper puts forward and studies a new control technique named 'IVF-MSPA' for switching converters.

First, the paper will introduce the basic principle of the IVF-MSPA control technique, then study the work characteristics and controlling regulation of Boost converter operating in DCM as an example, finally verify the feasibility and advantages of IVF-MSPA control technique through the simulation and experimental results.

\section{Principle of IVF-MSPA Control Technique}

Unlike original pulse adjustment (PA) control technique realized by a combination of two different control pulses, IVF-MSPA control technique extends these two different pulses to multiple sets of control pulses. The principle of IVF-MSPA control technique is introduced as follows:

At the beginning of each switching period, the IVF-MSPA controller senses the input voltage and output voltage of DC-DC converter. The input voltage $V_{\text {in }}$ is compared with the pre-defined voltage boundary $\sigma_{\mathrm{n}-1}(\mathrm{n}=2,3)$ to determine which one set of $P_{1}^{H}$ and $P_{1}^{L}, P_{2}^{H}$ and $P_{2}^{L}, P_{3}^{H}$ and $P_{3}^{L}$ will be selected as the control pulses. At the same time, the output voltage $V_{0}$ is compared with desired voltage $V_{\text {ref }}$ to determine corresponding level pulse between $P_{j}^{H}$ and $P_{j}^{L}(j=1,2,3)$. When the output voltage is higher than the desired level, low-power pulse $P_{j}^{L}$ with shorter turn-on time is employed. On the contrary, when the output voltage is lower than the desired voltage, high-power pulse $P_{j}^{H}$ with longer turn-on time is used to drive the power switch. The longer the turn-on time, the more power is delivered to the load. As shown in Fig. 1, this is a IVF-MSPA controlled DC-DC converter operating in DCM, with IVF-MSPA consisting of three sets different control pulses $P_{1}^{H}$ and $P_{1}^{L}, P_{2}^{H}$ and $P_{2}^{L}, P_{3}^{H}$ and $P_{3}^{L}$ as an example.

At the beginning of each switching period, if $V_{\text {in }}<\sigma_{1}$, which means the input voltage is much lower than the rated input voltage, the highest level of a set of control pulse is employed sequentially; if $\sigma_{1}<V_{\text {in }}<\sigma_{2}$, which means the input voltage is close to the rated input voltage, the second higher level of a set of control pulse is employed sequentially; If $V_{\text {in }}>\sigma_{2}$, which means the input voltage is much higher than the rated input voltage, the lowest level of a set of control pulse is employed sequentially. According to the output voltage sensed, high-power pulse $P_{j}^{H}$ or low-power pulse $P_{j}^{L}$ is used, if $V_{\mathrm{o}}<V_{\text {ref }}$, high-power pulse $P_{j}^{H}$ is selected to drive the power switch; if $V_{\mathrm{o}}>$ $V_{\text {ref }}$, low-power pulse $P_{j}^{L}$ is selected to drive the power switch.

Above all, the IVF-MSPA controller selects one among multiple sets of control pulse according to the amplitude of the converter input voltage and emits the high-power pulse $P_{j}^{H}$ or low-power pulse $P_{j}^{L}$ according to the relationship between the output voltage of DC-DC converter and the desired voltage. A IVF-MSPA repetition cycle is consisted of pulse sequence constructed by the combination of $P_{j}^{H}$ and $P_{j}^{L}$.When the converter is operating in the steady-state, the IVF-MSPA controller emits the same pulse sequence repeatedly. 


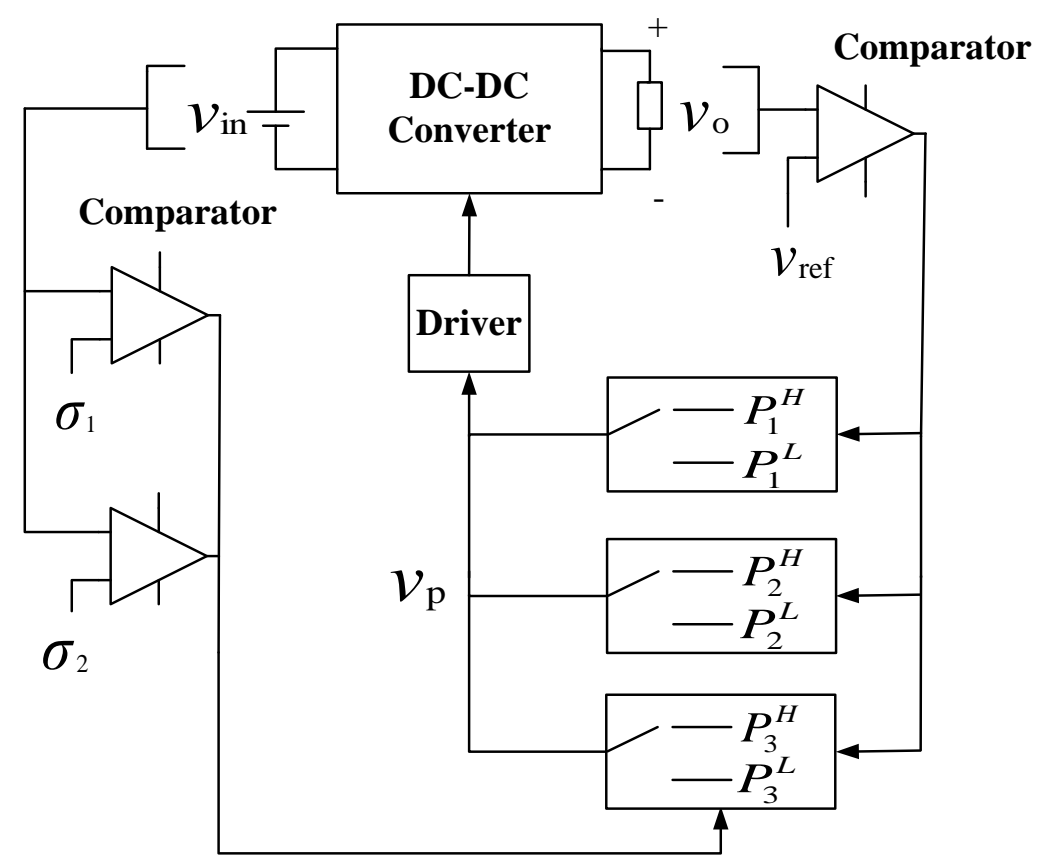

Fig.1 Block diagram of IVF-MSPA controller

\section{Analysis of the IVF-MSPA Controlled Boost Converter Operating in DCM}

\subsection{Steady-state Characteristics Analysis.}

As shown in Fig. 2, this is the Boost converter power circuit. Assuming that the Boost converter output voltage ripple can be ignored in each switching period, the analysis is introduced as follows.

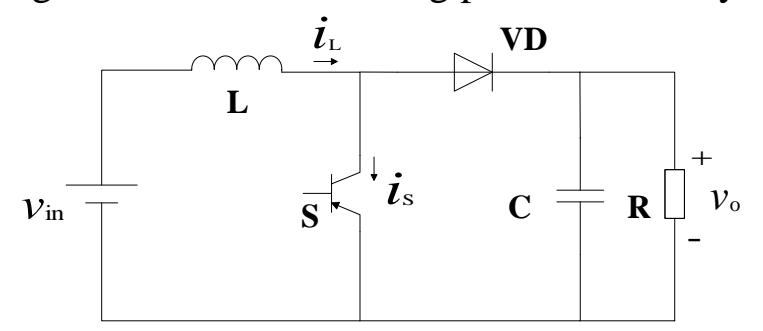

Fig.2 Diagram of Boost converter

Within $P_{j}^{H}$ and $P_{j}^{L}(j=1,2,3)$ control pulse cycle, the averaged current flowing from $V_{\text {in }}$ is respectively

$$
\begin{aligned}
I_{\mathrm{in}, \mathrm{Hj}} & =\frac{V_{\mathrm{o}} V_{\text {in }}}{2 L\left(V_{\mathrm{o}}-V_{\mathrm{in}}\right)} D_{\mathrm{Hj}}^{2} T, \quad j=1,2,3 \\
I_{\mathrm{in}, \mathrm{Lj}} & =\frac{V_{\mathrm{o}} V_{\text {in }}}{2 L\left(V_{\mathrm{o}}-V_{\text {in }}\right)} D_{\mathrm{Lj}}^{2} T
\end{aligned}
$$

Where the duty ratio of the $P_{j}^{H}$ and $P_{j}^{L}$ control pulse are $D_{\mathrm{Hj}}$ and $D_{\mathrm{Lj}}$, respectively.

The delivered energy from input during $P_{j}^{H}$ and $P_{j}^{L}$ control pulse cycle is respectively

$$
\begin{aligned}
& E_{\mathrm{in}, \mathrm{Hj}}=\frac{V_{\mathrm{o}} V_{\mathrm{in}}^{2}}{2 L\left(V_{\mathrm{o}}-V_{\mathrm{in}}\right)} D_{\mathrm{Hj}}^{2} T^{2} \\
& E_{\mathrm{in}, \mathrm{Lj}}=\frac{V_{\mathrm{o}} V_{\mathrm{in}}^{2}}{2 L\left(V_{\mathrm{o}}-V_{\mathrm{in}}\right)} D_{\mathrm{Lj}}^{2} T^{2}
\end{aligned}
$$

We assumes that the numbers of control pulses $P_{j}^{H}$ and $P_{j}^{L}$ within one IVF-MSPA repetition cycle are $\mu_{j}^{H}$ and $\mu_{j}^{L}$, respectively. Therefore the energy delivered from input during the IVF-MSPA repetition cycle is 


$$
\sum E_{\text {in }}=\mu_{j}^{H} E_{\text {in, } \mathrm{Hj}}+\mu_{j}^{L} E_{\text {in }, \mathrm{Lj}}
$$

During one IVF-MSPA repetition cycle, we have

$$
\left(\mu_{j}^{H}+\mu_{j}^{L}\right) P T=\eta \sum E_{\text {in }}
$$

Where $\eta$ is the power conversion efficiency of the Boost converter and $P=V_{\mathrm{o}}{ }^{2} / R$ is the power consumed by the load. Then by combining (2)-(4), we have

$$
P=\frac{\eta T V_{\mathrm{o}} V_{\mathrm{in}}^{2}\left(k_{j} D_{\mathrm{Hj}}^{2}+D_{\mathrm{L}}^{2}\right)}{2 L\left(V_{\mathrm{o}}-V_{\mathrm{in}}\right)\left(k_{j}+1\right)}
$$

Where the proportion of control pulses $P_{j}^{H}$ and $P_{j}^{L}$ within one IVF-MSPA repetition cycle is $k_{j}=\mu_{j}^{H} / \mu_{j}^{L}$.

From (5), we come to the conclusion that the parameters of $k_{j}, D_{\mathrm{Hj}}$ and $D_{\mathrm{Lj}}$ need to be changed to adapt to the changes in the input voltage of the Boost converter. An illustrative example, if the input voltage changes in the first amplitude range $\left(V_{\text {in }}<\sigma_{1}\right)$, by adjusting the pulse number ratio $k_{1}$, the IVF-MSPA controlled Boost converter is adapted to the variation of the input voltage, $D_{\mathrm{H} 1}$ and $D_{\mathrm{L} 1}$ are employed.

\subsection{The Design of the Control Parameters}

The IVF-MSPA control parameters are vitally important to achieve the control strategy and good control characteristics or not , the design of the IVF-MSPA control parameters is described in detail as follows.

The parameters of the Boost converter are given in Table 1.

Table 1 The parameters of the Boost converter

\begin{tabular}{ccc}
\hline Parameters & Signification & Value \\
\hline$V_{\text {in }} / \mathrm{V}$ & Rated input voltage & 6 \\
$V_{\mathrm{o}} / \mathrm{V}$ & Output voltage & 12 \\
$P / \mathrm{W}$ & Output power & 4.5 \\
$L / \mu \mathrm{H}$ & Inductor & 33 \\
$C / \mu \mathrm{F}$ & Filter capacitor & 2000 \\
$T / \mu \mathrm{s}$ & Switching cycle & 50 \\
\hline
\end{tabular}

The critical condition of the Boost converter operating in DCM is

$I_{\mathrm{o}} \geq I_{\mathrm{D}}$

Where $I_{\mathrm{o}}$ is the current flowing from the load and $I_{\mathrm{D}}$ is the averaged current flowing from the diode VD in one switching cycle. From (6), we have

$$
\frac{L}{R T}<\frac{D(1-D)^{2}}{2}
$$

Then according to the data in Table 1 , we deduce that any control pulse duty ratio $D$ must be less than 0.76 if the Boost converter operating in DCM.

Within only single control pulse cycle, analogizing from (5), we have

$$
P=\frac{\eta T V_{\mathrm{o}} V_{\text {in }}^{2} D^{2}}{2 L\left(V_{\mathrm{o}}-V_{\text {in }}\right)}
$$

Then by assuming $\alpha=P L, \beta=\eta T$, we deduce

$$
V_{\text {in }}=\frac{\sqrt{\alpha^{2}+2 \alpha \beta V_{\mathrm{o}}^{2} D^{2}}-\alpha}{\beta V_{\mathrm{o}} D^{2}}
$$

From (9), the Boost converter operating in $4 \mathrm{~V}$ input voltage, the duty ratio $D$ of the single control pulse is 0.47 . Analogously, the weighted average of the duty ratio of control pulses $P_{1}^{H}$ and $P_{1}^{L}$ within one IVF-MSPA repetition cycle is $\left(k_{1} D_{\mathrm{H} 1}+D_{\mathrm{L} 1}\right) /\left(k_{1}+1\right)=0.47$. In order to obtain lesser output voltage ripple, the difference between $D_{\mathrm{H} 1}$ and $D_{\mathrm{L} 1}$ should not be set too much, 
with $k_{1}=1$. Finally, we determine that the duty ratio $D_{\mathrm{H} 1}$ and $D_{\mathrm{L} 1}$ are 0.68 and 0.26 , respectively. According to the method described above, $D_{\mathrm{H} 2}$ and $D_{\mathrm{L} 2}, D_{\mathrm{H} 3}$ and $D_{\mathrm{L} 3}$ are determined respectively (listed in Table 2).

Table 2 The parameters of the IVF-MSPA control

\begin{tabular}{ccc}
\hline Parameters & Signification & Value \\
\hline$D_{\mathrm{H} 1}$ & Duty ratio of control pulse $P_{\mathrm{H} 1}$ & 0.68 \\
$D_{\mathrm{L} 1}$ & Duty ratio of control pulse $P_{\mathrm{L} 1}$ & 0.26 \\
$D_{\mathrm{H} 2}$ & Duty ratio of control pulse $P_{\mathrm{H} 2}$ & 0.48 \\
$D_{\mathrm{L} 2}$ & Duty ratio of control pulse $P_{\mathrm{L} 2}$ & 0.16 \\
$D_{\mathrm{H} 3}$ & Duty ratio of control pulse $P_{\mathrm{H} 3}$ & 0.28 \\
$D_{\mathrm{L} 3}$ & Duty ratio of control pulse $P_{\mathrm{L} 3}$ & 0.12 \\
$\sigma_{1} / \mathrm{V}$ & Reference input voltage & 5 \\
$\sigma_{2} / \mathrm{V}$ & Reference input voltage & 7 \\
\hline
\end{tabular}

\subsection{Control Pulse Combination}

From (5), we deduce that $k_{j}$ as a function of $V_{\text {in }}$ is

$$
k_{j}=\frac{2 P L\left(V_{\mathrm{o}}-V_{\mathrm{in}}\right)-\eta T V_{\mathrm{o}} D_{\mathrm{Lj}}^{2} V_{\mathrm{in}}^{2}}{\eta T V_{\mathrm{o}} D_{\mathrm{Hj}}^{2} V_{\mathrm{in}}^{2}-2 P L\left(V_{\mathrm{o}}-V_{\mathrm{in}}\right)}
$$

Therefore, equation (10) and Figure 3a can be used to estimate the proportion of IVF-MSPA control pulses at any input voltage.

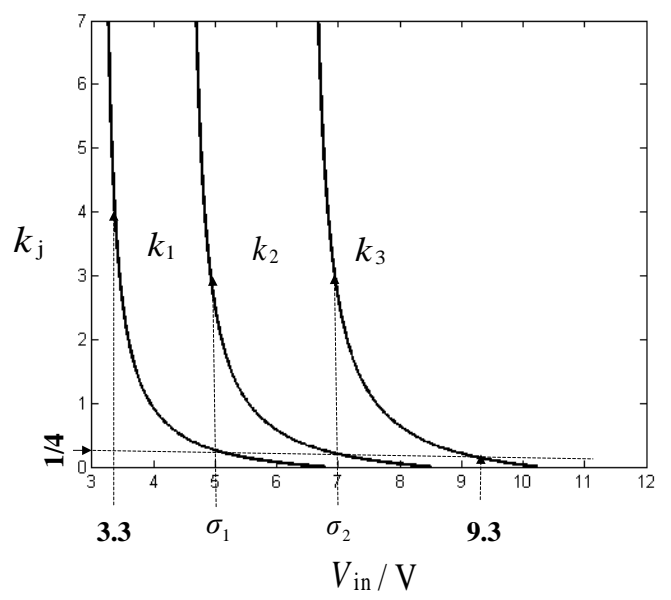

(a) The IVF-MSPA control

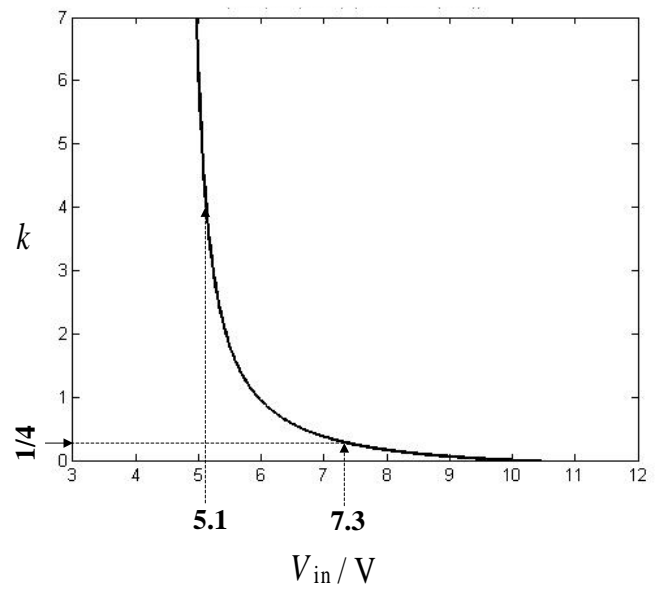

(b) The PA control

Fig. $3 k_{j}$ or $k$ as a function of input voltage $V_{\text {in }}$

From Fig 3a, we know that the IVF-MSPA controlled Boost converter can normally operate under input voltage variations from $3.3 \mathrm{~V}$ to $9.3 \mathrm{~V}, k_{j}$ varying between $1 / 4$ and 4 . The larger $k_{j}$ than 4 and the smaller $k_{j}$ than 1/4, the larger the output voltage ripple. From Fig 3b, we deduce that the PA controlled Boost converter can normally operate under input voltage variations from $5.1 \mathrm{~V}$ to 7.3V, $k_{j}$ varying between $1 / 4$ and 4 .

In conclusion, the applicable input voltage scope of the IVF-MSPA controlled Boost converter is much wider than the PA controlled Boost converter. 


\section{Simulation Results}

Simulations are performed using the same parameters given in Table 1 and Table 2. Fig.4 shows the steady-state waveforms of the IVF-MSPA controlled Boost converter operating in the rated input voltage $6 \mathrm{~V}$.

Fig.4 Steady-state waveforms of IVF-MSPA converter for $6 \mathrm{~V}$ input voltage

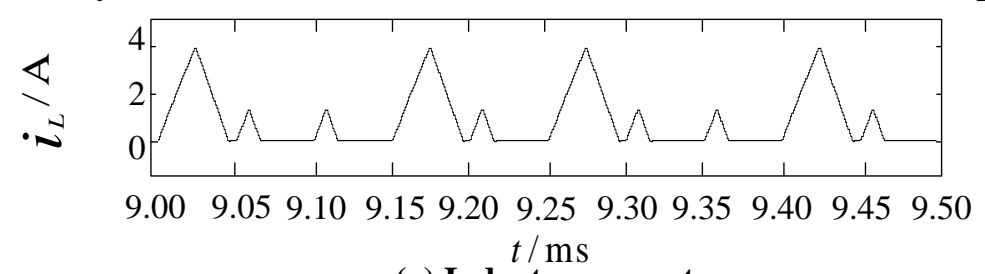

(a) Inductor current
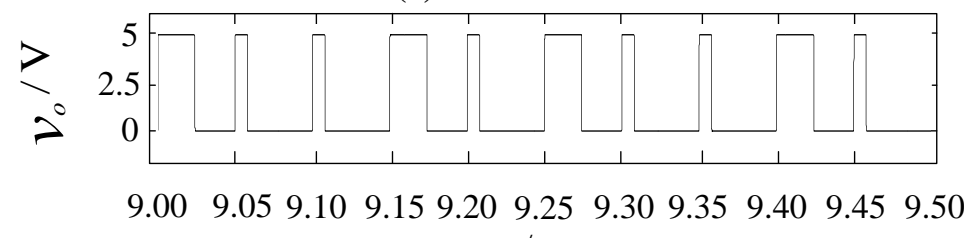

$t / \mathrm{ms}$

(b) Control pulses

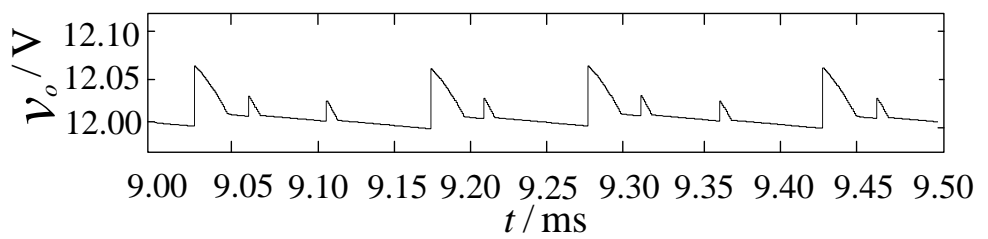

(c) Output voltage

From Fig.4b, we can know that the control pulses within the IVF-MSPA repetition cycle are $P_{2}^{H}-2 P_{2}^{L}-P_{2}^{H}-P_{2}^{L}$, and the proportion $k_{2}$ of the IVF-MSPA control pulses is $2 / 3$.

From Fig.4c, we can deduce that the output voltage of the IVF-MSPA converter is $12 \mathrm{~V}$, and the voltage ripple is $65 \mathrm{mV}$.

The waveforms of IVF-MSPA and PA controlled converter under input voltage variations are shown in Fig.5. From Fig.5, we can see the output voltage ripple of the IVF-MSPA control is 70mV, input voltage varying from $3.5 \mathrm{~V}$ to $5 \mathrm{~V}$ to $7 \mathrm{~V}$ to $9 \mathrm{~V}$, while the output voltage ripple of the PA control is $100 \mathrm{mV}$, input voltage varying from $5 \mathrm{~V}$ to $7 \mathrm{~V}$.

From Fig.5a, we can know that there is no obvious rise for the output voltage of the IVF-MSPA controlled converter under input voltage varying from $5 \mathrm{~V}$ to $7 \mathrm{~V}$; from Fig.5b, we can see that there is a little rise for the output voltage of the PA controlled converter under input voltage varying from $5 \mathrm{~V}$ to $7 \mathrm{~V}$.

From the discussion above, we deduce that the output voltage ripple of the IVF-MSPA control is lower than the PA control under input voltage variations, and compared with the PA controlled converter, the IVF-MSPA controlled converter enjoys excellent steady and transient state performance and the wider input voltage scope. 


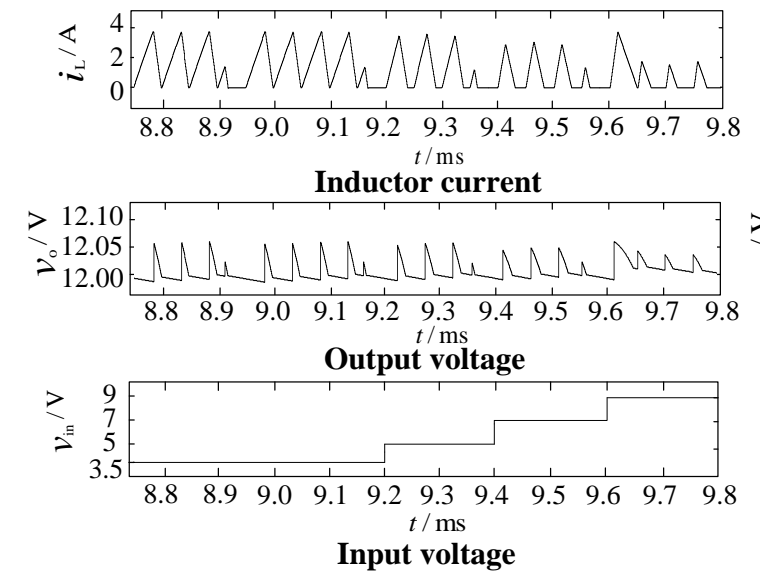

(a) IVF-MSPA control

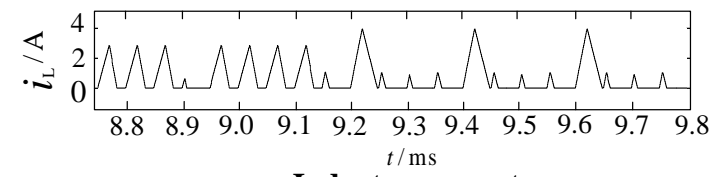

Inductor current

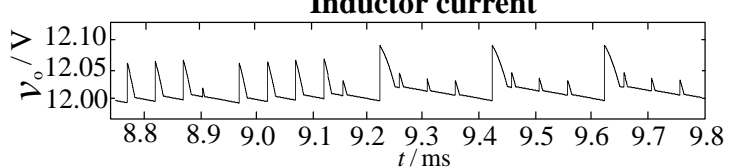

Output voltage

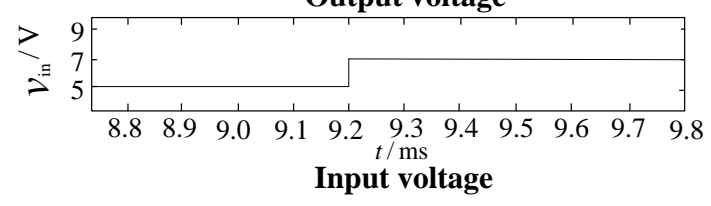

(b) PA control

Fig.5 Waveforms of IVF-MSPA and PA controlled converter under input voltage variations

\section{Experimental Results}

Experiments are also performed using the same parameters given in Table 1 and Table 2. The waveforms of the IVF-MSPA controlled converter under different input voltage $(4 \mathrm{~V}, 6 \mathrm{~V}, 8 \mathrm{~V})$ are shown in Fig.6 fig.8.

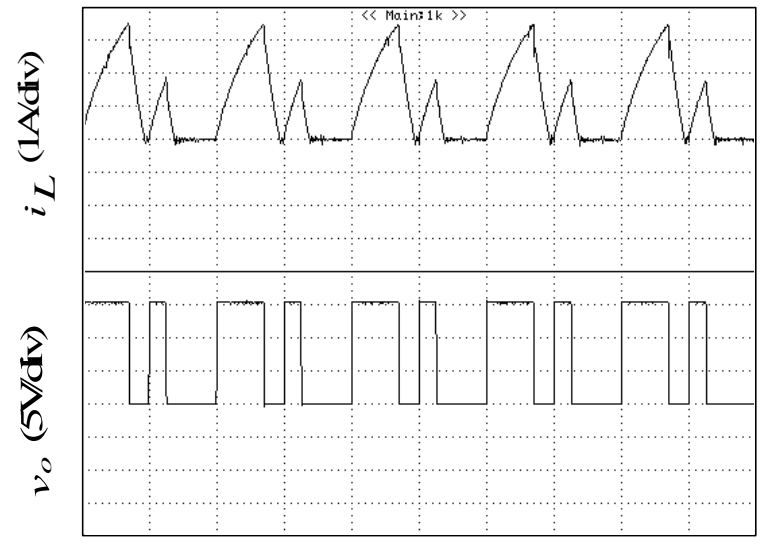

$t(50 \mu \mathrm{s} / \mathrm{div})$

Inductor current and control pulses

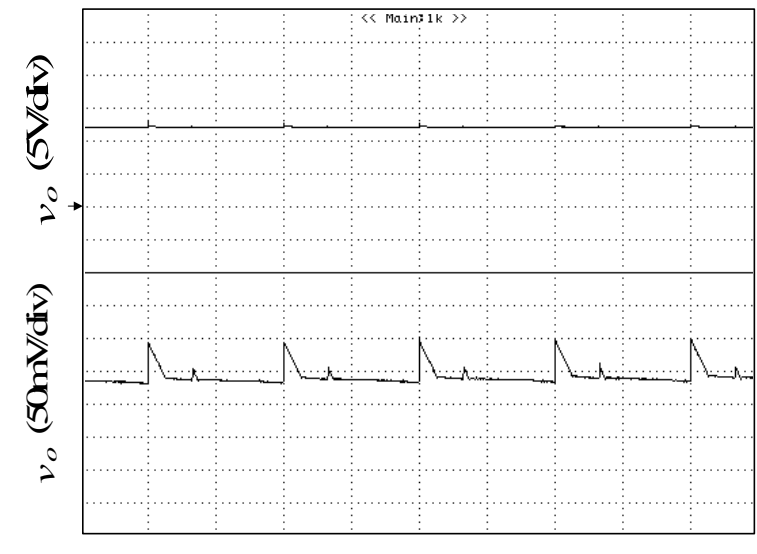

$t(50 \mu s /$ div $)$

Output voltage and voltage ripple

Fig.6 Experimental results of IVF-MSPA control for 4V input voltage

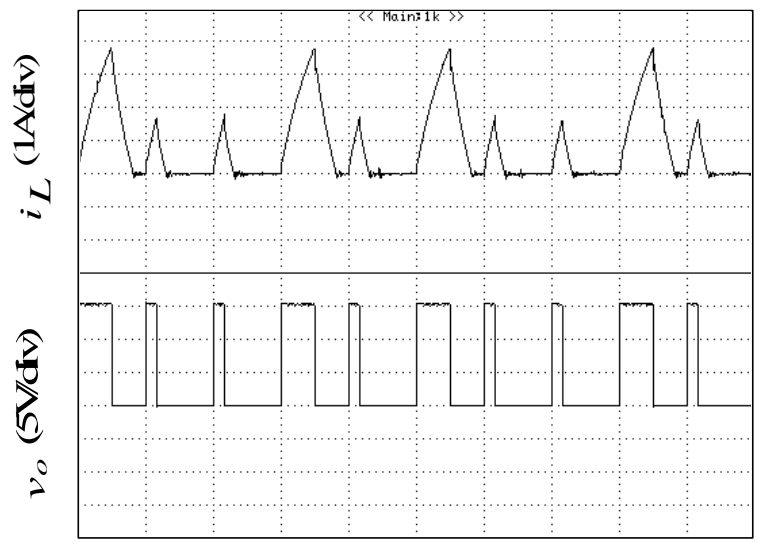

$t(50 \mu s$ / div $)$

Inductor current and control pulses

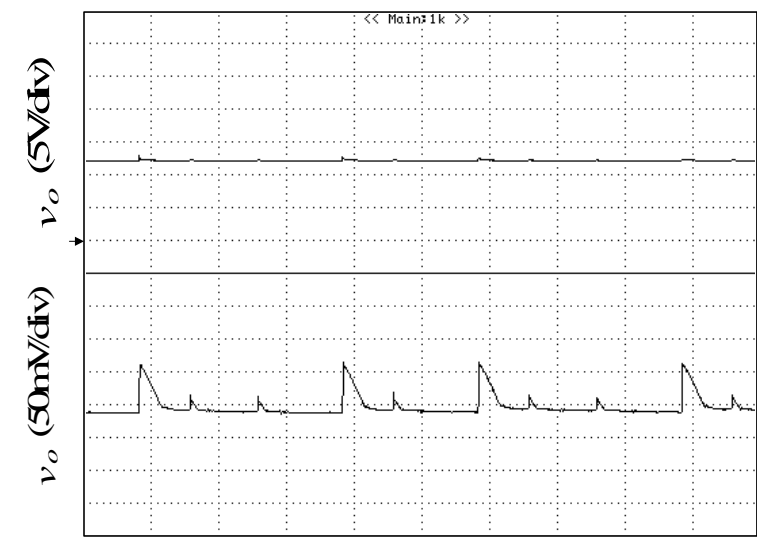

$t(50 \mu \mathrm{s} / \mathrm{div})$

Output voltage and voltage ripple

Fig.7 Experimental results of IVF-MSPA control for 6V input voltage 

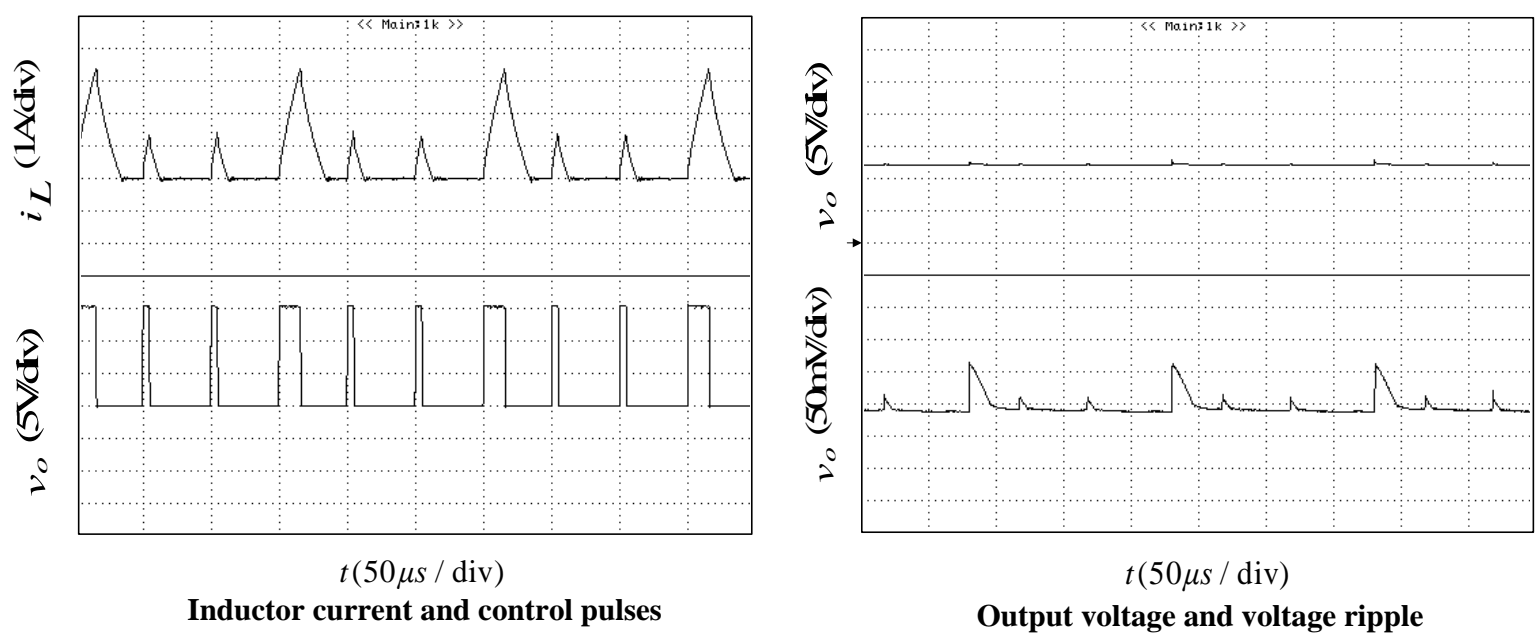

Fig.8 Experimental results of IVF-MSPA control for 8V input voltage

The waveforms of the PA controlled converter under $4 \mathrm{~V}$ input voltage are given in Fig.9, from which is known that the PA converter can not normally operate in steady-state so that the output voltage $11 \mathrm{~V}$ is much lower than the desired voltage $12 \mathrm{~V}$.
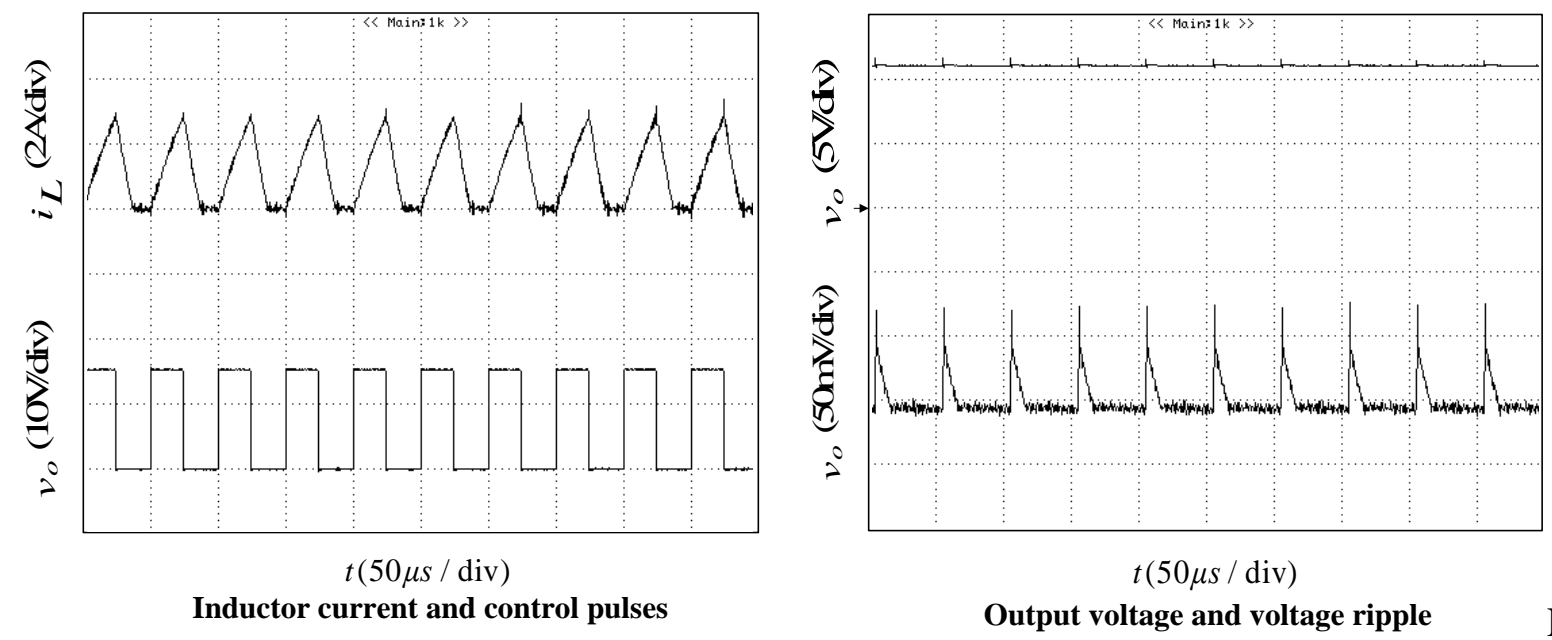

9 The waveforms of the PA control for $4 \mathrm{~V}$ input voltage

\section{Summary}

Multiple Sets of Pulse Adjustment Based on Input Voltage Feed-forward Compensation (IVF-MSPA), a new control technique for DC-DC converters is proposed and studied in the paper. Boost converter operating in DCM is taken as an example to illustrate the principle and control regulation of IVF-MSPA control scheme. Theory analysis, simulation results and experimental results show that the IVF-MSPA controlled converter enjoys good steady and transient state performance as well as the wider input voltage scope compared with the PA controlled converter.

\section{Acknowledgement}

The research work is supported by the National Natural Science Foundation of China under project number 51207142 and China Postdoctoral Science Foundation under project number $2012 \mathrm{M} 521408$.

\section{References}

[1]. WU F, SUN X, JIANG Y. Effect of DC micro-grid periodical ripple on output power of photovoltaic system and its elimination[J]. Electric Power Automation Equipment, 2014, 34 (3): 
34-39.

[2]. WANG J, ZHU X, SU H, et al Proportional-resonant control for Z-source inverter in three-phase PV grid-connected system[J]. Electric Machines and control, 2010, 14 (4): 86-91.

[3]. DING M, WANG W, WANG X, et al A review on the effect of large-scale PV generation on power systems[J]. Proceedings of the CSEE, 2014, 34 (1):1-14.

[4]. KADRI R, GAUBERT J -P, CHAMPENOIS G. Non-dissipative string current diverter for solving the cascaded DC-DC converter connection problem in photovoltaic power generation system[J].IEEE Transactions on Power Electronics, 2012, 27 (3): 1249-1258.

[5]. MOZINA C J. Impact of green power distributed generation[J]. IEEE Industry Applications Magazine, 2010, 16 (4): 55-62.

[6]. SUN D, GE B, LIANG W, et al An energy stored Quasi-Z-Source cascade multilevel inverter based photovoltaic power generation system[J]. IEEE Transactions on Industrial Electronics, 2015, 62 (9): 5458-5467.

[7]. LIANG J, MOLINA D D, VENAVAGAMOORTHY G K, et al Two-Level dynamic stochastic optimal power flow control for power systems with intermittent renewable generation[J].IEEE Transactions on Power Systems ,2013, 28 (3): 2670-2678.

[8]. YAO C, RUAN X, CAO W, et al An input voltage feed-forward control strategy for two-switch Buck-Boost DC-DC converters[J]. Proceedings of the CSEE, 2013, 33 (21): 36-44.

[9]. LI Y, GAO Y, HOU X. Development of PWM control technology in multi-level converters[J]. Power Electronics,2005, 39 (5): 5-9.

[10]. SHA J, XU J. Study on control pulse combination of pulse train controlled switching converter and its multi-periodicity analysis[J]. Acta Physica Sinica, 2013, 62 (21): 412-424.

[11]. XU J, WANG J. Bi-frequency Pulse-train control technique for switching DC-DC converters operating in DCM[J]. IEEE Transactions on Industrial Electronics, 2011, 58 (8): 3658-3667.

[12]. KHALIGH A, RAHIMI A M, EMADI A. Negative impedance stabilizing pulse adjustment control technique for DC-DC converters operating in discontinuous conduction mode and driving constant power loads[J].IEEE Transactions on Vehicular Technology, 2007, 56 (4): 2005-2016.

[13]. QIN M, XU J. Multi-duty ratio modulation technique for switching DC-DC converters operating in discontinuous conduction mode [J]. IEEE Transactions on Industrial Electronics, 2010, 57 (10): 3497-3507.

[14]. YUE C, QIN M, WANG Y. Study on pulse train controlled pseudo-continuous conduction mode DC-DC converter based on DSP [J]. Electric Welding Machine, 2015,45 (11): 21-25.

[15]. QIN M, XU J, WANG J, et al Multilevel pulse train controlled Boost converter[J]. Electric Machines and control, 2009, 13 (4): 533-538. 